fared no better than others in this respect. Misprints are very numerous. Not all are calculated to raise a smile, in the reading of a serious and important book, as is the following (p. xxxv). 'The doctors therefore owe it to ping the public and patients, to assist Government in stop both this rot and finding a proper solution of the manpower problem.' [Read stopping].

\title{
D. M. DUNLOP
}

Selected Writings of Lord Moynihan: A Centenary Volume, London, Pitman Medical Publishing Co., for The Osler Club of London, 1967, pp. xiv, 177, illus., 63s. $0 d$. This book, which is designed as a centenary tribute to Lord Moynihan, who was born on 2 October 1865, includes an admirable short biography by A. White Franklin; a charming note by W. R. Bett about the meeting of the Osler Club on 19 March 1930 at which Moynihan was a guest, and made a never-to-be-forgotten contribution to the discussion; a comprehensive list of his books and articles; and a note by Geoffrey Bateman on Moynihan's biographer, Donald Bateman.

The selection of the contents, only ten out of the list of 200 publications, with the intention of presenting a comprehensive picture of Moynihan's personality and interests, must have been an unenviable task: and the small group responsible are to be congratulated on the result of their deliberations.

The Ritual of Surgical Operation was an obvious choice; the papers on The Pathology of the Living and The Gifts of Surgery to Medicine indicate his appreciation of the potential of clinical research in its earliest days; the Murphy Oration and the Hunterian Oration show his sense of history, and though he did not refer directly to it, of his own place in 'the Great Procession'; and in many of the papers there are references to his professional ideals, and his advocacy of collaboration rather than competition between physicians and surgeons in the interests of their patients. One only regrets that room was not found for the Harveian Oration to the Medical Society of London in 1926, Before and After Operation, since it is not generally recognized how extensively he applied physiological principles using methods which are commonly regarded as much later innovations.

It is an elegant little volume, well suited to its purpose; and it is particularly pleasing that Franklin and Bett who in 1928, while still students, founded the Osler Club of London, should participate in its production.

JAMES PATERSON ROSS

Bulletin de la Société Française d'Histoire de la Médecine, vol. I (1902), photographic reproduction, Paris, Ateliers R. Lacer, 1967, 48 F.

Recent technical progress greatly benefits historians. Due to new methods of reproduction for which the term Reprography has been coined, old and out-of-print texts leave the library shelves to reach the historian in his own study, thus providing working tools difficult to obtain in the past.

The Société Française d'Histoire de la Médecine is publishing in facsimile its Bulletin (1902-1951), which has been out of print for many years, at the rate of two volumes monthly. The first volume contains articles by such well-known historians as Paul Delaunay, Victor Nicaise and Eugene Gley. Among the thirty-four original papers 